NASA Technical Memorandum 110162

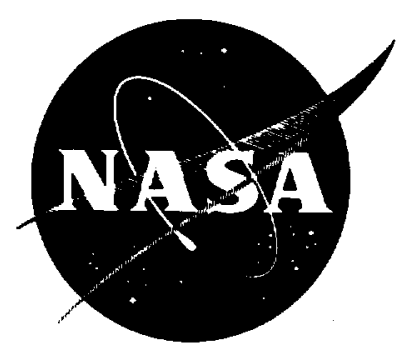

\title{
Formulation of an Improved Smeared Stiffener Theory for Buckling Analysis of Grid-Stiffened Composite Panels
}

Navin Jaunky and Norman F. Knight, Jr.

Old Dominion University, Norfolk, Virginia

Damodar R. Ambur

Langley Research Center, Hampton, Virginia

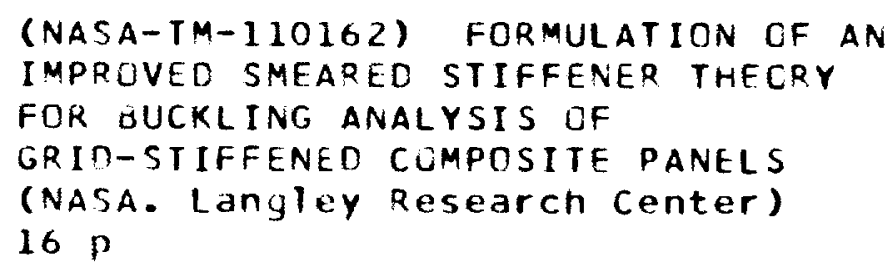

June 1995

National Aeronautics and

Space Administration Langley Research Center

Hampton, Virginia 23681-0001 



\title{
FORMULATION OF AN IMPROVED SMEARED STIFFENER THEORY FOR BUCKLING ANALYSIS OF GRID-STIFFENED COMPOSITE PANELS
}

\author{
Navin Jaunky and Norman F. Knight, Jr. \\ Old Dominion University \\ Norfolk, VA 23529-0247 \\ Damodar R. Ambur \\ NASA Langley Research Center \\ Hampton, VA 23681-0001
}

\begin{abstract}
A smeared stiffener theory for stiffened panels is presented that includes skinstiffener interaction effects. The neutral surface profile of the skin-stiffener combination is developed analytically using the minimum potential energy principle and statics conditions. The skin-stiffener interaction is accounted for by computing the stiffness due to the stiffener and the skin in the skin-stiffener region about the neutral axis at the stiffener. Buckling load results for axially stiffened, orthogrid, and general grid-stiffened panels are obtained using the smeared stiffness combined with a Rayleigh-Ritz method and are compared with results from detailed finite element analyses.
\end{abstract}

\section{INTRODUCTION}

In aircraft structures, structural efficiency dictates that most primary structures be of stiffened construction. The advent of high-performance composite materials combined with low-cost automated manufacturing using filament-winding and towplacement techniques has made grid-stiffened structural concepts a promising alternative to more traditional stiffened structural concepts. Their damage tolerant characteristics (Ref. 1) and stiffness tailoring potential (Ref. 2) make grid-stiffened structures attractive for structural applications.

An aircraft in flight is subjected to air loads which are imposed by maneuver and gust conditions. These forces on a structural panel that result from these external loads are shown in Figure 1. These internal loads, which depend on the location of the panel in an aircraft structure, may result in overall panel buckling, local buckling of the skin between stiffeners, and stiffener crippling. Hence, an efficient and accurate buckling analysis method for general grid-stiffened panels subjected to combined inplane loading is needed in order to design grid-stiffened structural panels for different locations in fuselage and wing structures.

Most of the research work on stiffened panels presented in the literature addresses axially stiffened panels subjected to compression. A limited amount of work has been 
reported on stiffened panels subjected to combined in-plane loading. Axially stiffened panels subjected to axial compression and in-plane shear was considered by Stroud, et al. (Ref. 3). Gendron and Gurdal (Ref. 4) considered grid-stiffened composite cylindrical shells subjected to axial compression and torsional shear. The modeling approaches generally used in the analysis of stiffened panels include the discrete approach (Ref. 5), the branched plate and shell approach (Refs. 3 and 4), and the smeared stiffener approach (Refs. 6-9). In the discrete stiffener approach, stiffeners are modeled as lines of axial bending and torsional stiffnesses on the skin. This approach is difficult to use when the panel is stiffened in more than two directions and when the stiffener is not symmetric about the skin mid-surface. The branched plate and shell approach is more flexible and more accurate and usually involves the use of finite element analysis (Ref. 4). However, the detailed spatial discretization of the finite element model is tedious, and the solution is computationally expensive. In the smeared stiffener approach, the stiffened panel is converted mathematically to an unstiffened uniform thickness panel with equivalent orthotropic stiffnesses. These equivalent or smeared stiffnesses can be used in a Rayleigh-Ritz method to solve for buckling loads of the stiffened panel. The smeared stiffener approach is computationlly efficient to execute and can easily account for stiffeners in any direction. The smeared stiffener approach is applicable in general to stiffened panels where the local buckling load is equal to or greater than the global buckling load. This approach for preliminary design is consistent with the aeronautical design philosophy where a buckling-resistant design is the design goal.

In Refs. 8 and 9, a first-order shear-deformation theory (FSDT) has been used for developing an analysis tool based on a smeared stiffener approach. As observed in Refs. 3 and 9 , the traditional or conventional smeared stiffener approach may overestimate the buckling load of stiffened panels in a certain range of geometric parameters because the traditional smeared stiffener approach does not account for local skin-stiffener interactions. This effect should be included in an improved smeared stiffener approach to make the approach a more reliable tool for the analysis and design of grid-stiffened panels. This paper describes an approach to incorporate the effects of local skin-stiffener interaction into a smeared stiffener theory and presents numerical results for panel buckling loads from the traditional and improved smeared stiffener theories.

\section{ANALYTICAL APPROACH}

The approximate stiffness added by a stiffener to the skin stiffness can be determined by locating the position of the neutral surface in a skin-stiffener combination. The location of the neutral surface is determined theoretically through a study of the local stress distribution near the skin-stiffener interface similar to the approach presented in Ref. 10 for a panel with a blade stiffener. However, the study presented in Ref. 10 does not provide a general solution that is applicable to all classes of symmetric laminates. 
A grid-stiffened panel may be considered to be an assembly of repetitive units or unit cells (see Figure 2). Any stiffener segment in the unit cell may be isolated in a semi-infinite skin-stiffener model as shown in Figure 2 for a diagonal stiffener. An approach for obtaining the stress distribution in a semi-infinite stiffened panel is outlined below.

The average membrane stresses in the local coordinate system of the semi-infinite stiffened panel model are obtained by combining the constitutive relations with the strain compatibility equations and the use of a stress function approach. As a result, the following fourth-order partial differential equation is obtained.

$$
A_{11}^{*} \frac{\partial^{4} F}{\partial y^{4}}-2 A_{26}^{*} \frac{\partial^{4} F}{\partial x^{3} \partial y}+\left(2 A_{12}^{*}+A_{66}^{*}\right) \frac{\partial^{4} F}{\partial x^{2} \partial y^{2}}-2 A_{16}^{*} \frac{\partial^{4} F}{\partial x \partial y^{3}}+A_{22}^{*} \frac{\partial^{4} F}{\partial x^{4}}=0
$$

where $A_{i j}^{*}$ is given by $\left[A_{i j} / t\right]^{-1}$, the $A_{i j}$ are the extensional stiffness coefficients of the skin and $t$ is the thickness of the skin. Dividing Equation (1) by $A_{11}^{*}$ and transforming the $y$ coordinate by $\eta=e_{0} y$ results in

$$
\frac{\partial^{4} F}{\partial x^{4}}-2 e_{0} \frac{A_{26}^{*}}{A_{11}^{*}} \frac{\partial^{4} F}{\partial x^{3} \partial \eta}+e_{0}^{2} \frac{\left(2 A_{12}^{*}+A_{66}^{*}\right)}{A_{11}^{*}} \frac{\partial^{4} F}{\partial x^{2} \partial \eta^{2}}-2 e_{0}^{3} \frac{A_{16}^{*}}{A_{11}^{*}} \frac{\partial^{4} F}{\partial x \partial \eta^{3}}+\frac{\partial^{4} F}{\partial \eta^{4}}=0
$$

where $e_{0}=\left[A_{11}^{*} / A_{22}^{*}\right]^{1 / 4}$. This equation is solved by assuming that stresses decay rapidly as the distance, $y$, away from the stiffener centerline becomes large, that the stresses are localized near the stiffener, and that a symmetric loading condition exists along the stiffener. The membrane stress function is assumed to be of the form

$$
F=\operatorname{Real}\left(e^{i m k\left(x+i r e_{0} y\right)}\right)=\operatorname{Real}\left(e^{i m k(x+i r \eta)}\right)
$$

where $k=\frac{\pi}{L}, m=1,2,3, \ldots$ and $r$ is an unknown, and $x$ and $y$ are local coordinates in the semi-infinite model. Substituting this stress function into the fourth-order differential equation results in a quartic equation in terms of the unknown $r$. The roots of the quartic equation are computed using subroutine CXPOLY from the Mathematical and Statistical Software (Ref. 11) at NASA Langley Research Center. The roots of the quartic equation occur as two pairs of complex numbers given by

$$
r=\left\{\begin{array}{l} 
\pm r_{R 1}+i r_{I 1} \\
\pm r_{R 2}+i r_{I 2}
\end{array}\right.
$$

The membrane solution corresponds to the root with the largest magnitude of the real part for $r$ and is developed as follows

$$
\begin{gathered}
F_{1 m}=\operatorname{Real}\left[e^{i m k\left[x+i\left(r_{R}+i r_{I}\right) \eta\right]}\right]=e^{-r_{R} m k \eta} \cos \left[m k\left(x-r_{I} \eta\right)\right], \quad \text { for } \eta>0 \\
F_{2 m}=\operatorname{Real}\left[e^{i m k\left[x+i\left(-r_{R}+i r_{I}\right) \eta\right]}\right]=e^{-r_{R} m k \eta} \cos \left[m k\left(x+r_{I} \eta\right)\right], \quad \text { for } \eta<0 \\
F_{m}=\frac{A_{m}}{2}\left(F_{1 m}+F_{2 m}\right)=A_{m} e^{-m e_{0} r_{R}\left(y-t_{s} / 2\right)} \operatorname{Cos}[m k x] \operatorname{Cos}\left[m k e_{0} r_{I}\left(y-t_{s} / 2\right)\right]
\end{gathered}
$$

where $r_{R}$ and $r_{I}$ are the real and imaginary parts of the root, respectively, $t_{s}$ is the thickness of the stiffener, and $A_{m}$ are the unknown coefficients to be determined. 
A similar approach is taken for the bending solution using the fourth-order partial differential equation for the out-of-plane deflection in terms of the local coordinate system. That is,

$$
\frac{\partial^{4} w}{\partial x^{4}}+4 e_{b} \frac{D_{16}}{D_{11}} \frac{\partial^{4} w}{\partial x^{3} \partial \eta}+2 e_{b}^{2} \frac{\left(2 D_{12}+D_{66}\right)}{D_{11}} \frac{\partial^{4} w}{\partial x^{2} \partial \eta^{2}}+4 e_{b}^{3} \frac{D_{26}}{D_{11}} \frac{\partial^{4} w}{\partial x \partial \eta^{3}}+\frac{\partial^{4} w}{\partial \eta^{4}}=0
$$

where $D_{i j}$ are the bending stiffness coefficients of the skin, $e_{b}=\left[D_{11} / D_{22}\right]^{1 / 4}$ and $\eta=e_{b} y$. The solution for the out-of-plane deflection is obtained by assuming that the out-of-plane deflection decays as $y$ becomes large and that the loading is symmetric along the stiffener. The out-of-plane deflection is assumed to be of the form

$$
w=\operatorname{Real}\left(e^{i m k\left(x+i r e_{b} y\right)}\right)
$$

which on substitution into Equation (6) gives another quartic equation in $r$. The solution for the out-of-plane displacement corresponds to the root with the smallest non-zero magnitude of the real part for $r$ and is developed as follows

$$
\begin{gathered}
w_{1 m}=e^{i m k\left[x+i\left(r_{R b}+i r_{I b}\right) \eta\right]} \quad \text { for } \eta>0 \\
w_{2 m}=e^{i m k\left[x+i\left(-r_{R b}+i r_{I b}\right) \eta\right]} \quad \text { for } \eta<0 \\
w_{m}=\frac{1}{2} \operatorname{Real}\left[i B_{m} w_{1 m}+C_{m} w_{2 m}-i B_{m} w_{1 m}+C_{m} w_{2 m}\right] \\
w_{m}=e^{-m k e_{b} r_{R b}\left(y-t_{s} / 2\right)}\left\{B_{m} \sin \left[m k e_{b} r_{I b}\left(y-t_{s} / 2\right)\right]\right. \\
\left.+C_{m} \cos \left[m k e_{b} r_{I b}\left(y-t_{s} / 2\right)\right]\right\} \quad \operatorname{Cos}[m k x]
\end{gathered}
$$

where $r_{R b}$ and $r_{I b}$ are the real and imaginary parts of the root, respectively, and $B_{m}$ and $C_{m}$ are the unknown coefficients to be determined.

These two solutions (Equations (5) and (8) ) are valid near the skin-stiffener interface but not within the stiffener itself (i.e., $y \geq t_{s} / 2$ ). It is assumed that, since the stiffener is thin, the strain within the stiffener is approximately equal to the strain at the edge of the stiffener (at $y=t_{s} / 2$ ). The total strain energy, $U_{T}$, of the skin-stiffener combination is developed next from expressions for the out-of-plane deflection, $w_{m}$, and the membrane stress function, $F_{m}$. The total strain energy is obtained by evaluating the following integrals

1. The strain energy of the skin is

$$
U_{s k i n}=\int_{t_{0} / 2}^{\infty} \int_{-L}^{L}\left(\left\{\epsilon_{0}\right\}^{T}\left[A_{i j}\right]\left\{\epsilon_{0}\right\}+\{\kappa\}^{T}\left[D_{i j}\right]\{\kappa\}\right) d x d y
$$

where $\left\{\epsilon_{0}\right\}=\left\{\epsilon_{x}^{0} \epsilon_{y}^{0} \gamma_{x}^{0}\right\}$ are the membrane strains and $\{\kappa\}=\left\{\kappa_{x} \kappa_{y} \kappa_{x y}\right\}$ are the curvatures.

2. The strain energy of the stiffener is

$$
U_{s t i f f}=\frac{1}{2} \int_{t_{s} / 2}^{t_{s} / 2} \int_{-(t / 2+h)}^{-t / 2} \int_{-L}^{L} Q_{11}\left(\epsilon_{x}^{0}+z \kappa_{x}\right)_{y=t_{0} / 2}^{2} d x d z d y
$$

where $Q_{11}$ is the longitudinal modulus of the stiffener. 
3. The strain energy of the skin attached to the stiffener is

$$
U_{\text {attach }}=\frac{t_{s}}{2} \int_{-L}^{L}\left(A_{11}\left(\epsilon_{x}^{0}\right)_{y=t_{s} / 2}^{2}+D_{11}\left(\kappa_{x}\right)_{y=t_{*} / 2}^{2}\right) d x
$$

Hence, the expression for the total strain energy, $U_{T}$, is obtained by summing these contributions that results in

$$
U_{T}=C_{A} A_{m}^{2}+C_{B} B_{m}^{2}+C_{C} C_{m}^{2}+C_{A C} A_{m} C_{m}+C_{C B} C_{m} B_{m}
$$

where the coefficients $C_{A}, C_{B}, C_{C}, C_{A C}$ and $C_{C B}$ are obtained by evaluating the strain energy integrals.

The total bending moment developed at any cross section perpendicular to the longitudinal axis of the stiffener for the symmetric case can be represented by the series

$$
M=\sum_{m=1}^{\infty} M_{m}^{\prime}(y) \cos (m k x)
$$

From statics, the normal stresses over the cross section of plate-stiffener combination must satisfy the following conditions

$$
\begin{gathered}
2 \int_{t / 2}^{t / 2} \int_{t_{\bullet} / 2}^{\infty} \sigma_{x} d z d y+t_{s} \int_{-(t / 2+h)}^{t / 2} Q_{11}\left(\epsilon_{x}^{0}+z \kappa_{x}\right)_{y=t_{s} / 2} d z=0 \\
2 \int_{t / 2}^{t / 2} \int_{t_{s} / 2}^{\infty} z \sigma_{x} d z d y+t_{s} \int_{-(t / 2+h)}^{t / 2} z Q_{11}\left(\epsilon_{x}^{0}+z \kappa_{x}\right)_{y=t_{\bullet} / 2} d z \\
=\sum_{m=1}^{\infty} M_{m} \cos (m k x)
\end{gathered}
$$

where $t$ is the total thickness of the skin, $t_{s}$ is the total thickness of the stiffner, $h$ is the height of the stiffener above the outer surface of the skin, and $\sigma_{x}$ is the normal stress distribution over the cross-section. Evaluating the integrals defined by Equations (14) and (15) results in the following relations after neglecting coefficients of $\sin (m k x)$ which are due to the $A_{16}$ and $D_{16}$ terms in the extensional and bending stiffness matrices, respectively.

$$
\begin{gathered}
S_{11} A_{m}+S_{13} C_{m}=0 \\
S_{21} A_{m}+S_{22} B_{m}+S_{23} C_{m}=M_{m}
\end{gathered}
$$

Using Equations (16), the following expressions for $B_{m}$ and $C_{m}$ are obtained in terms of $A_{m}$ and $M_{m}$

$$
\begin{aligned}
& C_{m}=S_{11}^{*} A_{m} \\
& B_{m}=S_{21}^{*} A_{m}+S_{22}^{*} M_{m}
\end{aligned}
$$


where

$$
\begin{gathered}
S_{11}^{*}=-S_{11} / S_{13}, \quad S_{21}^{*}=\left(S_{11} S_{23}-S_{21} S_{13}\right) / S_{13} S_{22} \\
\text { and } \mathrm{S}_{22}^{*}=1 / \mathrm{S}_{22}
\end{gathered}
$$

Equations (17) are substituted into Equation (12) which is minimized with respect to $A_{m}$ to yield

$$
A_{m}=-V_{M} M_{m} / V_{A}
$$

where

$$
\begin{aligned}
V_{A} & =2\left(C_{A}+C_{B}\left(S_{21}^{*}\right)^{2}+C_{C}\left(S_{11}^{*}\right)^{2} C_{C B} S_{11}^{*} S_{21}^{*}\right. \\
V_{M} & =2 C_{B} S_{21}^{*} S_{22}^{*}+C_{C B} S_{11}^{*} S_{22}^{*}
\end{aligned}
$$

Using Equation (19), $B_{m}$ and $C_{m}$ can be expressed in terms of $M_{m}, V_{M}$ and $V_{A}$, with $M_{m}$ as the only unknown.

$$
\begin{aligned}
C_{m}=S_{11}^{*} A_{m} & =-S_{11}^{*} \frac{V_{M} M_{m}}{V_{A}} \\
B_{m}=S_{21}^{*} A_{m}+S_{22}^{*} M_{m} & =-S_{21}^{*} \frac{V_{M} M_{m}}{V_{A}}+S_{22}^{*} M_{m}
\end{aligned}
$$

The expression for axial strain in the skin-stiffener combination is obtained from the stress function, $F$, and the out-of-plane deflection, $w$, which is given by

$$
\epsilon_{x}=\frac{1}{\left(A_{11} / t\right)} \frac{\partial^{2} F}{\partial y^{2}}-z \frac{\partial^{2} w}{\partial x^{2}}
$$

Substituting for $A_{m}, B_{m}$ and $C_{m}$ in Equation (22) from Equations (19) and (21) and on solving for the value of $z$ for which $\epsilon_{x}$ is zero, an expression for the neutral surface, $Z^{\prime}(y)$ is obtained. Only one term $(m=1)$ in the series expansion is used to obtain the expression for $Z^{\prime}(y)$.

$$
Z^{\prime}(y)=\left(t / A_{11}\right) \frac{\partial^{2} F}{\partial y^{2}} / \frac{\partial^{2} w}{\partial x^{2}}
$$

where

$$
\begin{aligned}
\frac{t}{A_{11}} \frac{\partial^{2} F}{\partial y^{2}}= & -\frac{1}{\left(A_{11} / t\right)} \frac{V_{M} M_{m}}{V_{A}} e_{0}^{2} k^{2} m^{2} E x p\left[-m k e_{0} r_{R}\left(y-t_{s} / 2\right)\right] \cos [m k x] \times \\
& \left\{\left(r_{R}^{2}-r_{I}^{2}\right) \cos \left[m k e_{0} r_{I}\left(y-t_{s} / 2\right)\right]+2 r_{R} r_{I} \sin \left[m k e_{0} r_{I}\left(y-t_{s} / 2\right)\right]\right\} \\
\frac{\partial^{2} w}{\partial x^{2}}= & -k^{2} m^{2} E x p\left[-m k e_{b} r_{R b}\left(y-t_{s} / 2\right)\right] \cos [m k x] \times \\
& \left\{\left(-S_{11}^{*} \frac{V_{M} M_{m}}{V_{A}}\right) \cos \left[m k e_{b} r_{I b}\left(y-t_{s} / 2\right)\right]\right. \\
& \left.+\left(-S_{21}^{*} \frac{V_{M} M_{m}}{V_{A}}+S_{22}^{*} M_{m}\right) \sin \left[m k e_{b} r_{I b}\left(y-t_{s} / 2\right)\right]\right\}
\end{aligned}
$$


The expression for $Z^{\prime}(y)$ is independent of $M_{m}$ and the axial distance $x$. Since the expression for $Z^{\prime}$ involves $E x p\left[m k\left(e_{b} r_{R b}-e_{0} r_{R}\right)\left(y-t_{2} / 2\right)\right]$, the choice of roots for the solution of the stress function, $F$, and the out-of-plane deflection, $w$, ensures that the neutral surface $Z^{\prime}(y)$ decays as the distance away from the centerline, $y$, becomes large. Finally, the shift in the neutral surface at the stiffener is obtained by setting $y=t_{s} / 2$ in the expression for $Z^{\prime}(y)$.

$$
Z_{n}=-\frac{e_{0}^{2}\left(r_{R}^{2}-r_{I}^{2}\right)}{\left(A_{11} / t\right) S_{11}^{*}}
$$

A typical profile of the neutral surface for a skin-stiffener combination is shown in Figure 3. The distance $y^{*}$ represents the distance from the centerline of the stiffener to the point where the neutral surface coincides with the mid-surface of the skin. The average distance of the neutral surface over the distance $y^{*}$ is $Z^{*}$. The quantities $y^{*}$ and $Z^{*}$ are obtained numerically. The correction to the smeared stiffnesses due to the skin-stiffener interaction is introduced by computing the stiffness of the stiffener and the skin segment directly contiguous to it according to the following criteria.

1. If $y^{*}<t / 4$, then the reference surface for the stiffener is $Z_{n}$.

2. If $y^{*}>t / 4$, then the reference surface for the stiffener is $Z^{*}$.

In either case, the reference surface of the skin is taken to be its mid-surface.

\section{NUMERICAL RESULTS}

Three stiffened panels with different stiffener configurations and simply-supported boundary conditions are used as examples for the present analytical approach. Panel 1 is an axially-stiffened panel, Panel 2 is an orthogrid-stiffened panel, and Panel 3 is an example for a general grid-stiffened panel. Finite element analyses of these three panels have been conducted to verify the results for the present analytical approach. The finite element analysis codes STAGS (Ref. 12) and DIAL (Ref. 13) have been used for this purpose. In the STAGS finite element model, a nine-node shear-flexible element (i.e., STAGS element 480) is used while an eight-node isoparametric shear flexible element is used in the DIAL model. Finite element analysis results for all panels indicate that the panels buckle globally under the applied in-plane loading conditions.

\section{Panel 1}

Panel 1 is 30.0 -in. (762-mm.) long and 30.0-in. (762-mm.) wide with axial stiffeners only. The stiffener height and thickness are $1.86958 \mathrm{in.}(47.5 \mathrm{~mm}$.) and 0.20084 in. (5.1 mm.), respectively. The unit cell is 30.0 -in. (762-mm.) long and 10.0-in. (25.4-mm.) wide (see Figure 4). The skin ply stacking sequence is $[45 /-$ $45 /-45 / 45 / 0 / 90]_{s}$ with thicknesses of $0.00637 \mathrm{in}$. $\left(0.16 \mathrm{~mm}\right.$.) for the $45^{\circ}$ and $-45^{\circ}$ plies, 0.0249 in. $\left(0.63 \mathrm{~mm}\right.$.) for the $0^{\circ}$ plies and $0.0416 \mathrm{in}$. $\left(1.05 \mathrm{~mm}\right.$.) for the $90^{\circ}$ plies. The stiffener ply stacking sequence is $[45 /-45 /-45 / 45 / 0]_{s}$ with thicknesses 
of 0.00823 in. $(0.21 \mathrm{~mm}$.$) for the 45^{\circ}$ and $-45^{\circ}$ plies and $0.0675 \mathrm{in}$. $(1.71 \mathrm{~mm}$.) for the $0^{\circ}$ plies. The nominal ply mechanical properties used are: longitudinal modulus $=19.0 \mathrm{Msi}(131.16 \mathrm{E} 03 \mathrm{MPa})$; transverse modulus = 1.89 Msi (13.04E03 MPa); shear modulus $=0.93 \mathrm{Msi}(6.42 \mathrm{E} 03 \mathrm{MPa})$ and major Poisson's ratio $=0.38$.

The four panel load cases considered are shown in Table 1. The STAGS analysis results are compared with solutions from the smeared stiffener approach without skinstiffener interaction effects included (the traditional approach) and with skin-stiffener interaction effects included (the present approach). It can be seen that the value of $Z_{n}$ for the axial stiffener is not small compared to the height of the stiffener. The result obtained from the traditional approach is in good agreement with the STAGS analysis result for the case of axial compression and the result from present approach is less than the STAGS analysis result by 7.5 percent. For the other load cases shown in the Table, the results obtained by the traditional approach are greater than those of STAGS by 8 to 13 percent and those of the present approach are in good agreement with the STAGS results.

\section{Panel 2}

Panel 2 is 60.0-in. (1524-mm.) long and 36.0-in. (914.4-mm.) wide with axial and transverse stiffeners only. The stiffener height and thickness are 0.5 in. (12.7 $\mathrm{mm}$.$) and 0.12$ in. (3.0 mm.), respectively. The unit cell is 20.0 -in. (508-mm.) long and 9.0-in. (228.6-mm.) wide (see Fig. 5). The skin ply stacking sequence is $[45 /-45 / 90 / 0]$, and each ply thickness is $0.008 \mathrm{in}$. $(0.20 \mathrm{~mm}$.). The stiffener is made of material with $0^{\circ}$ orientation. The nominal ply mechanical properties used are: longitudinal modulus $=24.5 \mathrm{Msi}(169.13 \mathrm{E} 03 \mathrm{MPa})$; transverse modulus $=1.64$ Msi (11.32E03 MPa); shear modulus =0.87 Msi (6.0E03 $\mathrm{MPa})$ and major Poisson's ratio $=0.3$.

The panel buckling response when subjected to four loading conditions is indicated in Table 2. The DIAL analysis results are compared in Table 2 with solutions from the smeared stiffener approach without skin-stiffener interaction effects and with skin-stiffener interaction effects. The value of $Z_{n}$ for the transverse stiffener is not small compared to the height of the stiffener. The results obtained using the traditional approach overestimate the DIAL analysis result by 12.6 percent for the axial compression load case, by 4.0 percent for the transverse compression load case, and by 8.4 percent for the combined load cases. Results from the present approach agree with the DIAL analysis results except for the transverse compression load case where the present result is 5.2 percent less than the DIAL analysis result.

\section{Panel 3}

Panel 3 is 56.0-in. (1422.4-mm.) long and 20.0-in. (508-mm.) wide with transverse and diagonal stiffeners only. The stiffener height and thickness are 0.276 in. $(7.0 \mathrm{~mm}$.) and $0.1125 \mathrm{in}$. $(2.86 \mathrm{~mm}$.), respectively. The unit cell dimensions for this panel are 7.0 in. (177.8 mm.) in length and 5.0 in. (127 mm.) in width (see Fig. 6). The skin stacking sequence is $[45 / 90 /-45]_{s}$, and each ply thickness is 0.008 in. 
(0.20 mm.). The stiffener for this case is also made of $0^{\circ}$ material. The nominal ply mechanical properties used are: longitudinal modulus = 24.5 Msi (169.13E03 $\mathrm{MPa})$; transverse modulus $=1.64 \mathrm{Msi}(11.32 \mathrm{E} 03 \mathrm{MPa})$; shear modulus $=0.87(6.0 \mathrm{E} 03 \mathrm{MPa})$ Msi and major Poisson's ratio $=0.3$.

The panel was analyzed for the three load conditions shown in Table 3 . The DIAL analysis results are compared with results from the smeared stiffener approach without skin-stiffener interaction effects and with skin-stiffener interaction effects in Table 3. For this panel, the values of $Z_{n}$ are small compared to the height of the stiffener. The results obtained from the traditional approach are approximately 11 percent greater than the DIAL analysis results, and the results obtained using the present approach are approximately 6.5 less than the DIAL analysis results. For this panel, the results obtained using the present approach are conservative since the contribution of stiffness terms $A_{16}$ and $D_{16}$ in the expression for $\sigma_{x}$ are not small and influence the neutral surface profile position for the diagonal stiffener.

\section{CONCLUDING REMARKS}

An improved smeared stiffener theory that includes skin-stiffener interaction effects has been developed. The skin-stiffener interaction effects are introduced by computing the stiffness of the stiffener and the skin at the stiffener region about the neutral axis at the stiffener. The neutral surface profile for the skin-stiffener combination is obtained analyticaly through a study of the local stress distribution near the skin-stiffener interface.

The results from the numerical examples considered suggest that skin-stiffener interaction effects should be included in the smeared stiffener theory to obtain good corelation with results from detailed finite element analyses. In a few cases the present analysis appears to underestimate the buckling load by 5 to 7 percent. In spite of this limitation, the smeared stiffener theory with skin-stiffener interaction effects included is still a useful preliminary design tool and results in buckling loads that are more accurate than the results from the traditional smeared stiffener approach.

\section{REFERENCES}

1. Rouse, M.; and Ambur, D. R.: Damage Tolerance of a Geodesically Stiffened Advanced Composite Structural Concept for Aircraft Applications. Proceedings of the Ninth DOD/NASA/FAA Conference on Fibrous Composite in Structural Design, Lake Tahoe, Nevada, November 4-7, 1991. DOT/FAA/CT92-25 Vol. 2, pp. 1111-1121.

2. Ambur, D. R.; and Rehfield, L. W.: Effect of Stiffness Characteristics on the Response of Composite Grid-Stiffened Structures. AIAA Paper No. 91-1087CP, 1991. 
3. Stroud, J. W.; Greene, W. H.; and Anderson, S. M.: Buckling Loads of Stiffened Panels Subjected to Longitudinal Compression and Shear: Results Obtained with PASCO, EAL, and STAGS Computer Programs. NASA TP 2215, 1984.

4. Gendron, G.; and Gurdal, Z.: Optimal Design of Geodesically Stiffened Composite Cylindrical Shell. AIAA Paper No. 92-2306-CP, 1992.

5. Wang, J. T. S.; and Hsu, T. M.: Discrete Analysis of Stiffened Composite Cylindrical Shells. AIAA Journal, Vol. 23, No. 11, November 1985, pp. 17531761.

6. Dow, N. F.; Libove, C.; and Hubka, R. E.: Formulas for Elastic Constants of Plates with Integral Waffle-like Stiffening. NACA RM L53E1 3a, August 1953.

7. Troitsky, M. S.: Stiffened Plates, Bending, Stability and Vibrations. Elsevier Scientific Publishing Company, 1976.

8. Reddy, A. D.; Valisetty, R; and Rehfield, L. W.: Continuous Filament Wound Composites Concepts for Aircraft Fuselage Structures. Journal of Aircraft, Vol. 22, No. 3, March 1985, pp. 249-255.

9. Jaunky, N.: Elastic Buckling of Stiffened Composite Curved Panels. Master's Thesis, Old Dominion University, Norfolk, Virginia, August 1991.

10. Smith, C. B.; Heebink, T. B.; and Norris, C. B.: The Effective Stiffness of a Stiffener Attached to a Flat Plywood Plate. United States Department of Agriculture, Forest Products Laboratory, Report No. 1557, September 1946.

11. Anon: Mathematical and Statistical Software at Langley, Central Scientific Computing Complex. Document N-3, NASA Langley Research Center, April 1984.

12. Almroth, B. O.; Brogan, F. A.; and Stanley, G. M.: Structural Analysis of General Shells - User Instructions for STAGSC-1. Report LMSC-D633873, Lockheed Palo Alto Research Laboratory, December 1982.

13. Anon: DIAL Finite Element Analysis System-Version L3D2. Lockheed Missiles and Space Company, July 1987. 
Table 1: Results for axially stiffened panel (Panel 1).

X-stiffener: $Z_{n}=-0.4386$ in., $Z^{*}=-0.1020$ in., $y^{*}=4.7512$ in.

$Z_{n}=-11.14 \mathrm{~mm} ., Z^{*}=-2.59 \mathrm{~mm} ., y^{*}=120.67 \mathrm{~mm}$.

Critical Eigenvalue

\begin{tabular}{ccccc}
\hline \hline & & \multicolumn{3}{c}{ Critical Eigenvalue } \\
\cline { 3 - 5 }$N_{x}$ & $N_{x y}$ & STAGS & $\begin{array}{c}\text { Traditional } \\
\text { Approach }\end{array}$ & $\begin{array}{c}\text { Present } \\
\text { Approach }\end{array}$ \\
\hline lbs/in. & lbs/in. & & 9.9659 & 9.2135 \\
\hline 1000 & 0 & 9.9636 & 9.795 & 6.3483 \\
$(175.34)$ & $(0)$ & & & 4.9491 \\
\hline 0 & 1000 & 6.3016 & 6.7985 & \\
$(0)$ & $(175.34)$ & & & 5.5838 \\
\hline 1000 & 1000 & 4.9512 & 5.6018 & \\
$(175.34)$ & $(175.34)$ & & & 6.2007 \\
\hline 500 & 1000 & 5.5023 & & \\
$(87.67)$ & $(175.34)$ & & & \\
\hline \hline
\end{tabular}

Numbers within parentheses indicate loading in $\mathrm{N} / \mathrm{mm}$.

Table 2: Results for orthogrid panel (Panel 2).

X-stiffener: $Z_{n}=-0.0949$ in., $Z^{*}=-0.0165$ in., $y^{*}=0.0280$ in.

$Z_{n}=-2.41 \mathrm{~mm} ., Z^{*}=-0.42 \mathrm{~mm} ., y^{*}=0.71 \mathrm{~mm}$.

Y-stiffener: $Z_{n}=-0.1295$ in., $Z^{*}=-0.0177$ in., $y^{*}=0.0131$ in.

$Z_{n}=-3.29 \mathrm{~mm} ., Z^{*}=-0.45 \mathrm{~mm} ., y^{*}=0.33 \mathrm{~mm}$.

\begin{tabular}{cccccc}
\hline & & & \multicolumn{3}{c}{ Critical Eigenvalue } \\
\cline { 3 - 6 }$N_{x}$ & $N_{y}$ & $N_{x y}$ & DIAL & $\begin{array}{c}\text { Traditional } \\
\text { Approach }\end{array}$ & $\begin{array}{c}\text { Present } \\
\text { Approach }\end{array}$ \\
\hline lbs/in. & lbs/in. & lbs/in. & & 0.8903 & 0.8161 \\
\hline 400 & 0 & 0 & 0.7909 & 0.8903 & \\
$(70.14)$ & $(0)$ & $(0)$ & & & 0.5956 \\
\hline 0 & 200 & 0 & 0.6281 & 0.6536 & \\
$(0)$ & $(35.07)$ & $(0)$ & & & 0.3463 \\
\hline 400 & 200 & 0 & 0.3504 & 0.3799 & \\
$(70.14)$ & $(35.14)$ & $(0)$ & & & 0.3458 \\
\hline 400 & 200 & 50 & 0.3500 & 0.3796 & \\
$(70.14)$ & $(35.14)$ & $(8.77)$ & & & \\
\hline
\end{tabular}

Numbers within parentheses indicate loading in $\mathrm{N} / \mathrm{mm}$. 
Table 3: Results for grid-stiffened panel (Panel 3).

$$
\begin{aligned}
\text { Y-stiffener: } & Z_{n}=-0.0135 \mathrm{in} ., Z^{*}=-0.0043 \mathrm{in} ., y^{*}=2.3636 \mathrm{in} . \\
& Z_{n}=-0.34 \mathrm{~mm} ., Z^{*}=-0.11 \mathrm{~mm} ., y^{*}=60.0 \mathrm{~mm} . \\
\text { D-stiffener: } & Z_{n}=-0.0698, Z^{*}=-0.0349 \mathrm{in} ., y^{*}=0.0239 \mathrm{in} . \\
& Z_{n}=-1.77 \mathrm{~mm} ., Z^{*}=-0.89 \mathrm{~mm} ., y^{*}=0.61 \mathrm{~mm} .
\end{aligned}
$$

\begin{tabular}{cccccc}
\hline \hline & & & \multicolumn{3}{c}{ Critical Eigenvalue } \\
\cline { 3 - 6 }$N_{x}$ & $N_{y}$ & $N_{x y}$ & DIAL & $\begin{array}{c}\text { Traditional } \\
\text { Approach }\end{array}$ & $\begin{array}{c}\text { Present } \\
\text { Approach }\end{array}$ \\
\hline lbs/in. & lbs/in. & lbs/in. & & 0.3646 & 0.3045 \\
\hline 0.0 & 400 & 0.0 & 0.3290 & 0.30 & \\
$(0.0)$ & $(70.14)$ & $(0.0)$ & & & 0.3008 \\
\hline 0.0 & 400 & 300 & 0.3224 & 0.3595 & \\
$(0.0)$ & $(70.14)$ & $(52.60)$ & & & 0.2917 \\
\hline 100 & 400 & 300 & 0.3121 & 0.3486 & \\
$(17.53)$ & $(70.14)$ & $(52.60)$ & & & \\
\hline \hline
\end{tabular}

Numbers within parentheses indicate loading in $\mathrm{N} / \mathrm{mm}$. 


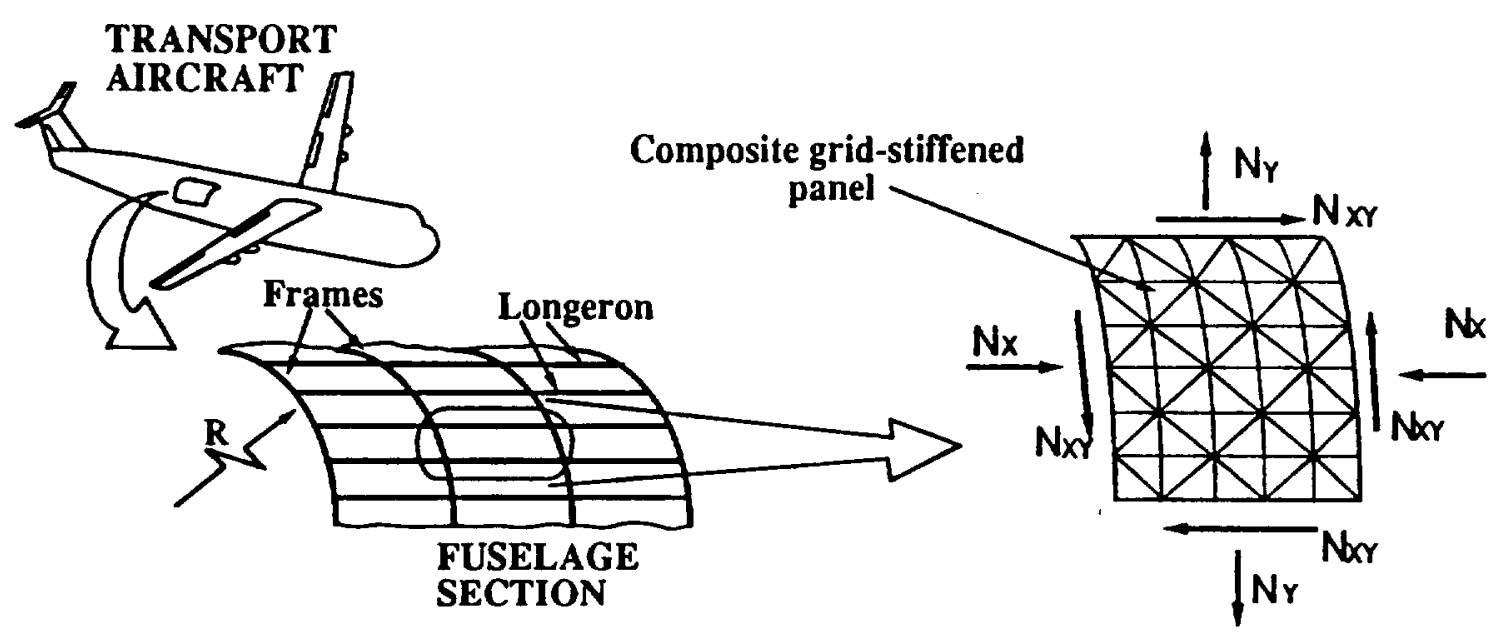

Figure 1. Aircraft structural applications showing internal forces.

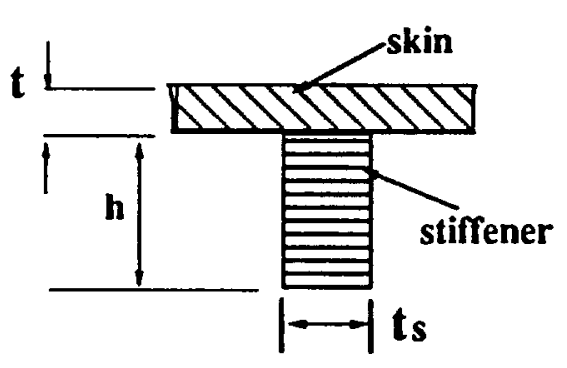

SECTION A-A

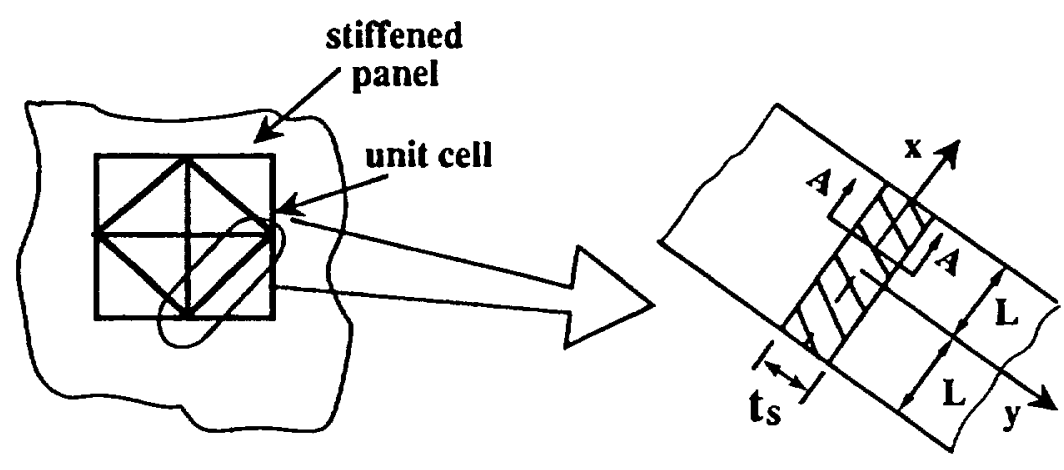

SEMI-INFINITE PLATE MODEL

Figure 2. Semi-infinite plate model for a skin-stiffener element.

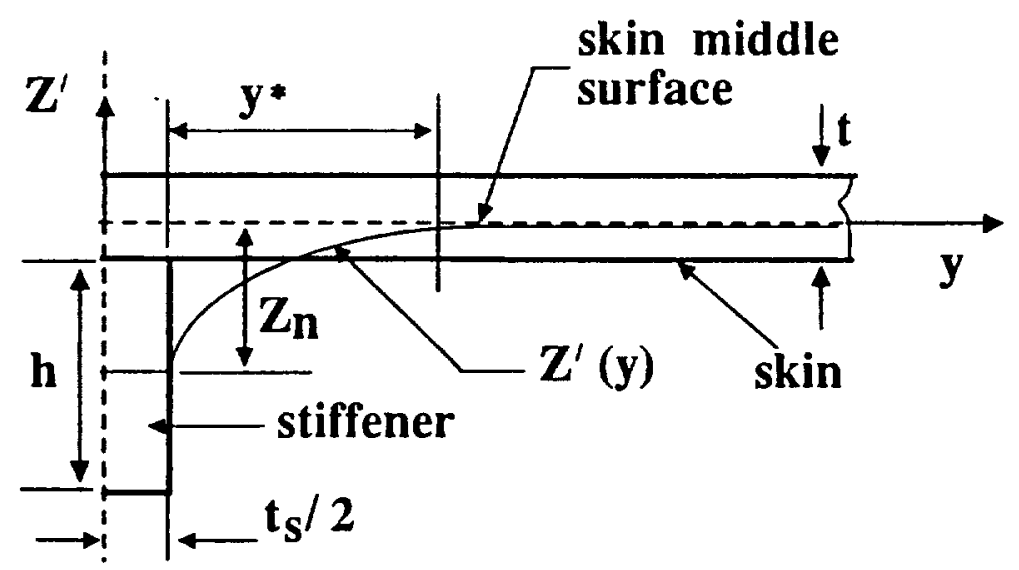

Figure 3. Typical profile of neutral surface for a skin-stiffener element. 


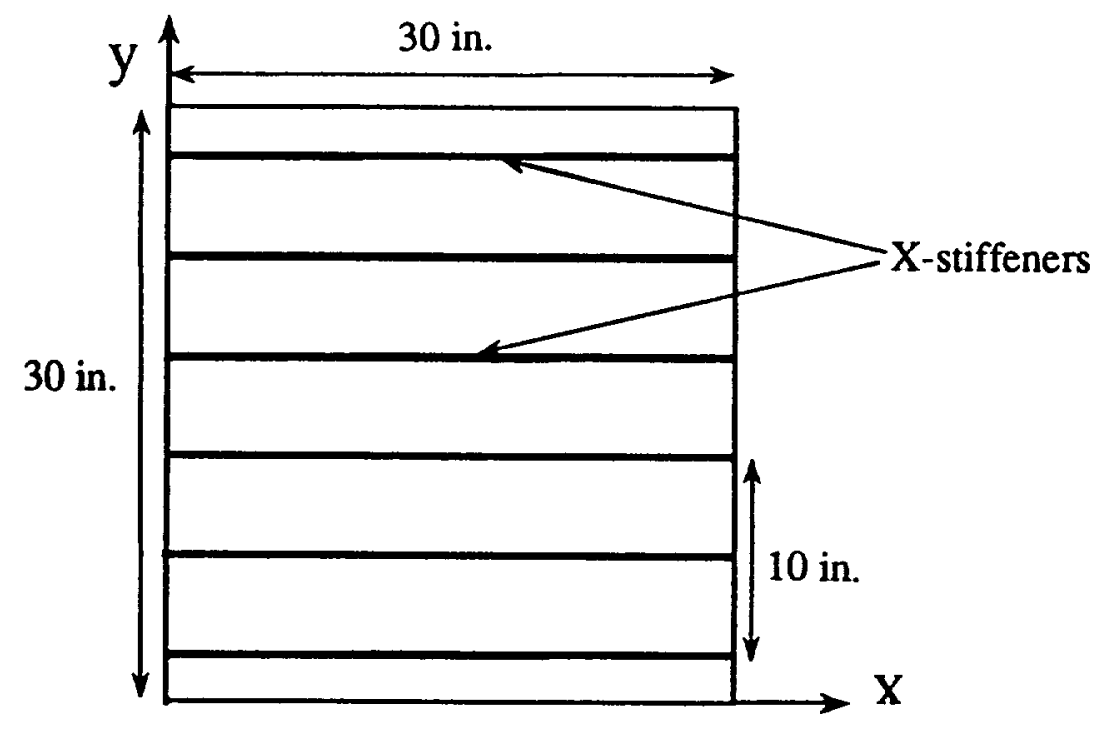

Figure 4. Axially stiffened panel

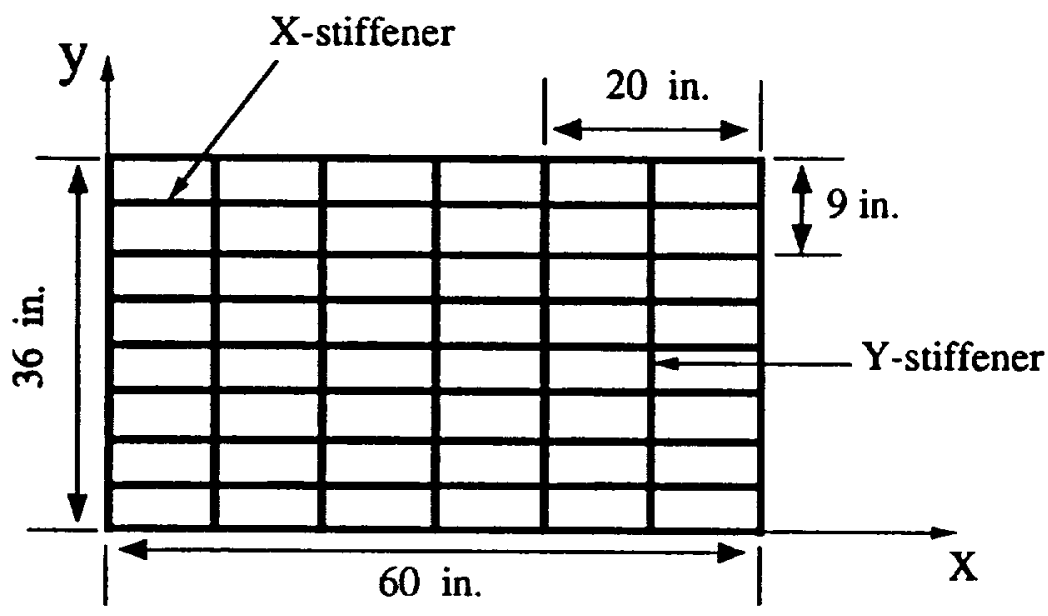

Figure 5. Orthogrid stiffened panel.

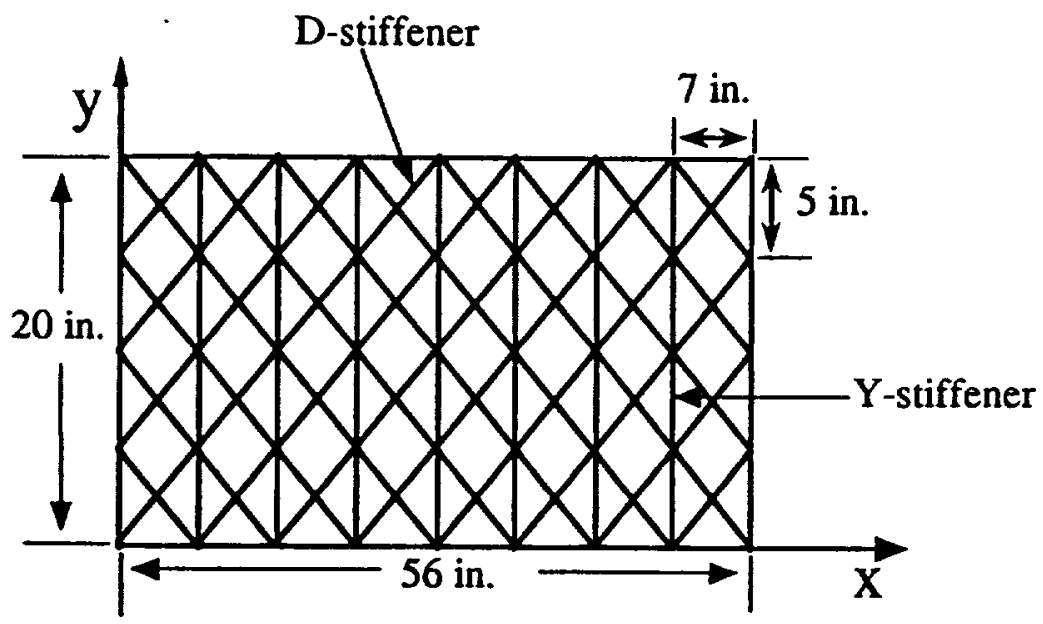

Figure 6. Grid-stiffened panel. 


\begin{tabular}{|c|c|c|c|c|}
\hline \multicolumn{4}{|c|}{ REPORT DOCUMENTATION PAGE } & $\begin{array}{l}\text { Form Approved } \\
\text { OMB No. 0704-018B }\end{array}$ \\
\hline \multicolumn{5}{|c|}{ 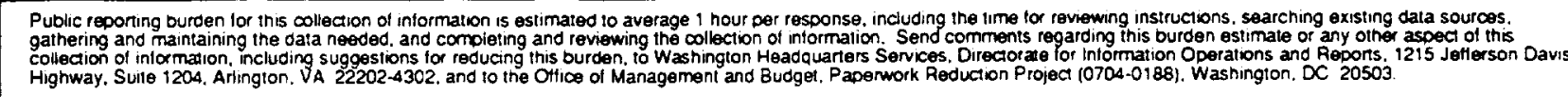 } \\
\hline 1. AGENCY USE ONLY (Leave blank) & \multicolumn{2}{|l|}{$\begin{array}{l}\text { 2. REPORT DATE } \\
\text { June } 1995\end{array}$} & \multicolumn{2}{|c|}{$\begin{array}{l}\text { 3. REPOAT TYPE AND DATES COVERED } \\
\text { Technical Memorandum }\end{array}$} \\
\hline \multicolumn{3}{|c|}{$\begin{array}{l}\text { 4. TITLE AND SUBTITLE } \\
\text { Formulation of an Improved Smeared Stiffener Theory for Buckling } \\
\text { Analysis of Grid-Stiffened Composite Panels }\end{array}$} & \multirow{2}{*}{\multicolumn{2}{|c|}{$\begin{array}{l}\text { 5. FUNDING NUMBERS } \\
\text { WU 510-02-12-01 }\end{array}$}} \\
\hline \multicolumn{3}{|c|}{$\begin{array}{l}\text { 6. AUTHOR(S) } \\
\text { Navin Jaunky, Norman F. Knight, Jr. and Damodar R. Ambur }\end{array}$} & & \\
\hline \multicolumn{3}{|c|}{$\begin{array}{l}\text { 7. PERFORMING ORGANIZATION NAME(S) AND ADDRESS(ES) } \\
\text { NASA Langley Research Center } \\
\text { Hampton, VA 23681-0001 }\end{array}$} & \multicolumn{2}{|c|}{$\begin{array}{l}\text { 8. PERFORMING ORGANIZATION } \\
\text { REPORT NUMBER }\end{array}$} \\
\hline \multicolumn{3}{|c|}{$\begin{array}{l}\text { 9. SPONSORING / MONITORING AGENCY NAME(S) AND ADDAESS(ES) } \\
\text { National Aeronautics and Space Administration } \\
\text { Washington, DC 20546-0001 }\end{array}$} & \multicolumn{2}{|c|}{$\begin{array}{l}\text { 10. SPONSORING / MONITORING } \\
\text { AGENCY REPORT NUMBER } \\
\text { NASA TM-110162 }\end{array}$} \\
\hline \multicolumn{5}{|c|}{$\begin{array}{l}\text { 11. SUPPLEMENTARY NOTES } \\
\text { Jaunky/Knight: Old Dominion University, Norfolk, VA.; Ambur: Langley Research Center, Hampton, VA. } \\
\text { Presented at the } 10 \text { th Internat"। Cont. on Composite Materials, British Columbia, Canada, August 14-18, } 1995 .\end{array}$} \\
\hline \multicolumn{3}{|c|}{$\begin{array}{l}\text { 12a. DISTRIBUTION / AVAILABILITY STATEMENT } \\
\text { Unclassified - Unlimited } \\
\text { Subject Category } 24\end{array}$} & \multicolumn{2}{|c|}{ 12b. DISTRIBUTION CODE } \\
\hline \multicolumn{5}{|c|}{$\begin{array}{l}\text { 13. ABSTRACT (Maximum } 200 \text { words) } \\
\text { A smeared stiffener theory for stiffened panels is presented that includes skin-stiffener interaction effects. The } \\
\text { neutral surface profile of the skin-stiffener combination is developed analytically using the minimum potential } \\
\text { energy principle and statics conditions. The skin-stiffener interaction is accounted for by computing the stiffness } \\
\text { due to the stiffener and the skin in the skin-stiffener region about the neutral axis at the stiffener. Buckling load } \\
\text { results for axially stiffened, orthogrid, and general grid-stiffened panels are obtained using the smeared stiffness } \\
\text { combined with a Rayleigh-Ritz method and are compared with results from detailed finite element analyses. }\end{array}$} \\
\hline \multirow{2}{*}{\multicolumn{4}{|c|}{$\begin{array}{l}\text { 14. SUBJECT TERMS } \\
\text { grid-stiffened plates, isogrid, buckling, composites, smeared stiffness, } \\
\text { combined loading }\end{array}$}} & $\begin{array}{l}\text { 15. NUMBER OF PAGES } \\
15\end{array}$ \\
\hline & & & & $\begin{array}{l}\text { 16. PRICE CODE } \\
\text { A03 }\end{array}$ \\
\hline $\begin{array}{l}\text { 17. SECURITY CLASSIFICATION } \\
\text { OF REPORT } \\
\text { Unclassified }\end{array}$ & $\begin{array}{l}\text { 18. SECURITY CLASSIFICATION } \\
\text { OF THIS PAGE } \\
\text { Unclassified }\end{array}$ & 19. SECUF & ITION & 20. LIMITATION OF ABSTRACT \\
\hline
\end{tabular}


